\title{
Prolonged PR Interval and Outcome in Cardiac Resynchronization Therapy
}

\author{
Jakrin Kewcharoen ${ }^{1}$ and Chanavuth Kanitsoraphan ${ }^{1}$ \\ University of Hawaii Internal Medicine Residency Program, ${ }^{1}$ Honolulu, HI - USA
}

\section{Dear Editor}

We read the article "Baseline Prolonged PR Interval and Outcome of Cardiac Resynchronization Therapy: A Systematic Review and Meta-analysis" by Rattanawong et al. ${ }^{1}$ with great interest. The authors investigated the effect of prolonged PR interval on composite outcome among patients who received cardio resynchronized therapy. The authors conclude that prolonged PR is associated with worse outcome in this population.

I would like to commend the authors for performing a systematic review and meta-analysis on this topic. The effect of prolonged PR interval was well-known in the general population. However, in this specific population, the answer is unclear and was in needed for answers, given almost half of the patients with cardiac resynchronization therapy (CRT) had $1^{\text {st }}$ degree AV block. ${ }^{2}$ Although several previous studies reported a negative impact on the cardiovascular outcome, they were retrospective cohort and was limited by a relatively small number of participants. Nevertheless, the authors demonstrated a good systematic review and performed the random-effect model with statistical perfection.

However, as the authors mentioned in the article, this meta-analysis has a limitation regarding the number of the included studies. Also, there is a difference in the cut-point

\section{Keywords}

Heart Failure;Cardiac resynchronization Therapy/methods; Meta-Analysis; Atrioventricular Block; Heart Conduction, System

Mailing Address: Jakrin Kewcharoen •

1212 Nuuanu ave, Honolulu, HI, 96817 - USA

Email address: jakrin@hawaii.edu

Manuscript received March 24, 2019, revised manuscript April 24, 2019, accepted April 24, 2019 for prolonged PR interval among the included studies. Although the study by Friedman et al. was the only study that used the cut-point of $230 \mathrm{~ms}$ instead of $200 \mathrm{~ms}$, they have the most included participants and has the most weight percentage in all three forest plots. We thought that this is a crucial point as a change in risk ratio of the study by Freidman et al. ${ }^{3}$ could potentially change the overall pooled RR of the meta-analysis.

There are two additional studies that we thought could be included in the meta-analysis that could affect the outcome of this meta-analysis. Studies by Stockburger et al. ${ }^{4}$ and Lin et al. ${ }^{5}$ evaluated the effect of PR interval in patients with CRT.

Stockburger et al. ${ }^{4}$ performed a post hoc analysis from the Multicenter automatic defibrillator implantation trial with cardiac resynchronization therapy (MADIT-CRT) trial. The authors found that patients with CRT who had short PR interval ( $<230 \mathrm{~ms}$ ) generally had worse outcome regarding heart failure and all-cause mortality, regardless of the QRS duration, although the authors did not directly compare the prolonged PR interval to normal PR interval.

Another study by Lin et al. ${ }^{5}$ was based on the secondary analysis of The Comparison of Medical Therapy, Pacing, and Defibrillation in Heart Failure (COMPANION) trial. The authors reported that the outcome of all-cause mortality was reduced in both normal and prolonged PR interval group when compared to medical therapy alone, but more so in the prolonged PR interval group. Moreover, in a multivariable Cox model, progressively longer baseline PR interval, as a continuous variable, was associated with an increasingly greater reduction in the primary outcome.

Given that results from these two studies reported a positive correlation between PR interval and cardiovascular outcome, including the data from the two studies could potentially change the outcome of this meta-analysis.

DOI: 10.5935/abc.20190101

\section{References}

1. Rattanawong P, Prasitlumkum N, Riangwiwat T, kanjanahattaki N, Vuthikraivit W, Chongsathidkiat P, et al. Baseline Prolonged PR Interval and Outcome of Cardiac Resynchronization Therapy: A Systematic Review and Meta-analysis. Arq Bras Cardiol. 2018;111(5):710-9.

2. Bristow MR, Saxon LA, Boehmer J, Krueger S, Kass DA, De Marco T, et al. Cardiac-resynchronization therapy with or without an implantable defibrillator in advanced chronic heart failure. The New England journal of medicine. 2004;350(21):2140-50.

3. Friedman DJ, Bao H, Spatz ES, Curtis JP, DaubertJP, Al-Khatib SM. Association between a prolonged PR interval and outcomes of cardiac resynchronization therapy: a report from the National cardiovascular Data-Registry. Circulation. 2016;134(21):1617-28.

4. Stockburger M, Moss AJ, Klein HU, Zareba W, Goldenberg I, Biton Y, et al.Sustained clinical benefit of cardiac resynchronization therapy in nonLBBB patients with prolonged PR-interval: MADIT-CRT long-term follow-up. Clin Res Cardiol. 2016;105(11):944-52.

5. Lin J, Buhr KA, Kipp R. Effect of PR Interval on Outcomes Following Cardiac Resynchronization Therapy: A Secondary Analysis of the COMPANION Trial. J Cardiovasc Electrophysiol. 2017;28(2):185-91. 


\section{Reply}

We appreciate the author's comments on our original article "Baseline Prolonged PR Interval and Outcome of Cardiac Resynchronization Therapy: A Systematic Review and Meta-analysis". ${ }^{1}$ We agree with the authors that the effect of PR interval in cardiac resynchronization therapy (CRT) population is unknown, and therefore we conducted a systematic review and meta-analysis on this topic.

We agree that the study by Friedman et al. ${ }^{2}$ has the most included participants and has the most percentage in all three forest plots. However, to evaluate the effect of Friedman et al., ${ }^{2}$ we performed a sensitivity analysis by excluding one study at a time which is shown in Supplementary Document 2 in the original article. ${ }^{1}$ After excluding Friedman et al., ${ }^{2}$ there was no significant change of the risk ratio of composite outcome (risk ratio $=1.19$, 95\% confidence interval: 1.04-1.36), all-cause mortality (risk ratio $=1.53,95 \%$ confidence interval: 1.23-1.91), and heart failure hospitalization (risk ratio $=1.6,95 \%$ confidence interval: 1.06-2.42). ${ }^{1}$ The meta-analysis pooled result still has a statistically significant risk ratio even if we exclude the study by Friedman et al. ${ }^{2}$ Therefore, a prolonged PR interval still predicts the outcomes of CRT regardless of the results of the study by Friedman et al. ${ }^{2}$

We appreciate the author's recommendation to include the study by Stockburger et al. ${ }^{3}$ and Lin et al. ${ }^{4}$ Both studies were included from our comprehensive search and both full-text articles were reviewed. However, both studies were excluded from our systematic review and meta-analysis for the following reasons.
The study by Lin et al. ${ }^{4}$ was excluded from our systematic review and meta-analysis due to an inappropriate comparison as demonstrated in Figure 1 of our original article. Their objective is to compare the outcomes between CRT and optimal pharmacologic therapy stratified by PR interval. Our meta-analysis compared the outcome of prolonged PR interval versus normal PR interval only in CRT patients.

Similarly, the study by Stockburger et al. ${ }^{3}$ was also excluded from our systematic review and meta-analysis due to an inappropriate comparator. Stockburger et al. ${ }^{3}$ reported that patients with prolonged $P R$ interval derived clinical benefit with reduction in heart failure or death from CRT when compared to an implantable cardioverter defibrillator. ${ }^{3}$ Therefore, their comparison was different from our study, which was prolonged PR interval versus normal PR interval in CRT patients.

Our systematic review and meta-analysis used comprehensive search methodology and strict inclusion and exclusion criteria; therefore our results are robust. We showed that a prolonged PR interval in CRT patients is significantly associated with an increased risk for all-cause mortality, composite outcome, and HF hospitalization when compared to normal PR interval in CRT patients. ${ }^{1}$

Rattanawong, Pattara

Prasitlumkum, Narut

Riangwiwat, Tanawan.

Kanjanahattakij, Napatt

Vutthikraivit, Wasawat

\section{References}

1. Rattanawong P, Prasitlumkum N, Riangwiwat T, Kanjanahattakij N, Vutthikraivit W, Chongsathidkiet P, et al. Baseline Prolonged PR Interval and Outcome of Cardiac Resynchronization Therapy: A Systematic Review and Meta-analysis. Arq Bras Cardiol. 2018;111(5):710-9.

2. Friedman DJ, Bao H, Spatz ES, Curtis JP, Daubert JP, Al-Khatib SM. Association Between a Prolonged PR Interval and Outcomes of Cardiac Resynchronization Therapy: A Report From the National Cardiovascular Data Registry. Circulation. 2016;134(21):1617-28.

3. Stockburger M, Moss AJ, Klein HU, Zareba W, Goldenberg I, Biton Y, et al Sustained clinical benefit of cardiac resynchronization therapy in non-LBBB patients with prolonged PR-interval: MADIT-CRT long-term follow-up. Clin Res Cardiol. 2016;105(11):944-52.

4. Lin J, Buhr KA, Kipp R. Effect of PR Interval on Outcomes Following Cardiac Resynchronization Therapy: A Secondary Analysis of the COMPANION Trial. J Cardiovasc Electrophysiol. 2017;28(2):185-91. 